\title{
ARCHITECTURAL FEATURES AND PRESERVATION OF ANCIENT RESIDENTIAL COMPLEXES OF THE CHANGS IN XIANGAN, XIAMEN
}

\author{
Xia Jin ${ }^{\mathrm{a}}$, Shang-chia Chiou ${ }^{\mathrm{b}}$ \\ ${ }^{a}$ Graduate School of the Design Doctoral Program, National Yunlin University of Science and Technology, 236859746@ qq.com \\ ${ }^{\mathrm{b}}$ Department of Architecture and Interior Design, National Yunlin University of Science and Technology, chiousc@yuntech.edu.tw
}

KEY WORDS: Styleguide Xiang'an, Changs ancient residential, Minnan architectural, Ancient architecture, Preservation maintenance

\begin{abstract}
:
Ancient architecture is an important cultural symbol of a nation, which has high historical, artistic and technology of cultural value. A building not only carries the creator of effort, but also the past with the future of the historical traditions and humanistic significance. It is not purely construction of artistic expression, even more the witness of the production and development of social groups. Therefore, it is not only the common cultural heritage of mankind, as more equally important to protect these ancient buildings for the promotion of spiritual civilization and local economic development. In recent years, China and other developing countries, which in the pursuit of rapid economic development, are also facing the problems of development and preservation, Especially influenced by the inherent "reform and innovation" traditional concepts, many ancient villages and buildings with rich cultural connotation are in a great danger.
\end{abstract}

Xiang'an is one of the six administrative regions of Xiamen, The Tungyuan village and numerous surrounding villages which in Xiang'an retain a large number of ancient buildings of Ming and Qing Dynasties, but it has not been given due attention, many ancient buildings are facing the crisis of disappearing. Changs ancient residential is one of typical Minnan architectural which located in Tungyuan village. its main feature is as follows: Cheng is before the rear is Cuo, Facing south, Three bays with double Hucuo , Red brick and White stone wall, Architectural form of Hard mountain type roof and Double cocked dovetail ridge. In this paper, on the basis of the fieldwork, In addition to the overall building community environment and monomer building surveying and mapping, photograph, record, and through the collection, interviews and analysis of relevant historical materials, etc. Grasping the historical background of Changs ancient residential building community, exploring the formation and characteristics of the overall layout of the community, analyzing the cultural connotation of the basic shape of each individual building and architectural decorative arts, and making recommendations for saving Changs ancient residential maintenance.

\section{INTRODUCTION}

\subsection{Research Background}

Reportedly, Tungyuan Village in Xiangan District, Fujian Province was originally the residence of the Lis. In the Ming Dynasty, the Changs from Tungyuan Village in Qiongshanbao, Kinmen Island moved here to raise duck, and borrowed the hill corner in the east of brook from the Lis to build a hut to live. Afterwards, a village was gradually formed, and was named after the former village in Kinmen where the Changs lived. Because this village is located in the southeastern corner of the Lis' residence, it is called Tungyuan. This settlement is in a strip shape. According to the statistics in 1998, there were 1,648 households living in this village, with a total of 5,007 residents. The last name of most of the residents is Chang, and that of only 100 or so is Li. According to "Tongan Gazetteer," Jingqian Chang, the seventh son of Jing-qi Chang from Changlinshe in Jinjiang during the reign of emperor Gaozong of Song, moved to Qingyu, Kinmen to break new ground. Jing-qian Chang's grandson, Ji-yue Chang, moved to Gihontong, Tongan in the Southern Song Dynasty. Bi-yi Chang, the seventh generation of the Changs, brought his son, Yue-suo Chang, to move inland in the east of Putong of the Lis' residence in Xiangfeng, Tongan to escape from Japanese pirates during the reign of emperor Jiajing in the Ming Dynasty to build duck houses to raise ducks. Therefore, this settlement is called Tungyuan. The couplet in the ancestral temple of the Changs says, "We shall always remember our former residence in Qingyu, as well as Tungyuan where our offspring is bred (青屿 流香远，东园世泽长).” Apparently, the ancestral residence of the Changs is Qingyu in Kinmen. Jian-nan Ting, the chairman of Fujian Province Collector Association said, "'Complete' Minnan historic residence is known as the 'root' of cross-strait culture. However, due to the erosion of time, lack of repairs, severe theft and damage, lack of protection, Minnan historic residence have gradually disappeared. In recent years, although the cross-strait exchange and cooperation have constantly and profoundly upgraded the creative industry in Taiwan and Mainland China, importance has not been attached to the development of creative industry of 'Minnan historic residence' with strong Minnan cultural atmosphere." Historic residence in Tungyuan Village, Xiangan is no exception. It's a shame that complexes of historic residence have been replaced by new modern residence built with concrete. This study intends to reflect the historical and cultural value of Minnan historic residence, as well as to properly preserve and reutilize it.

\subsection{Research Method}

This study used field survey to measure, draw, photograph, and record overall environment of architectural complexes and single buildings, as well as used research methods, such as collection of relevant historical materials, interviews, and statistical analyses, to understand the historical background of ancient residential complexes of the Changs, investigate the 
formation and features of overall layout of settlement, analyze the basic patterns of various single buildings and cultural meanings of architectural decoration and art, and propose suggestions on preservation and maintenance of residential complexes of the Changs.

\section{SPATIAL STRUTURE AND LAYOUT OF SETTLEMENT}

\subsection{Material Basis - From Geographical Environment}

Architectural residential complexes of the Changs are located in Tungyuan natural Village, Xindian Township, Xiangan District, Xiamen City, Fujian Province. Tungyuan Village is adjacent to Xiangan Campus of Xiamen University. Its north is Xiangshan Mountain Range, its south is Dadeng Island and Taiwan Island. Tungyuan is distant from Kinmen, the ancestral residence of some of the overseas Chinese, Hong Kong, Macau, and people in Taiwan (Figure 1).

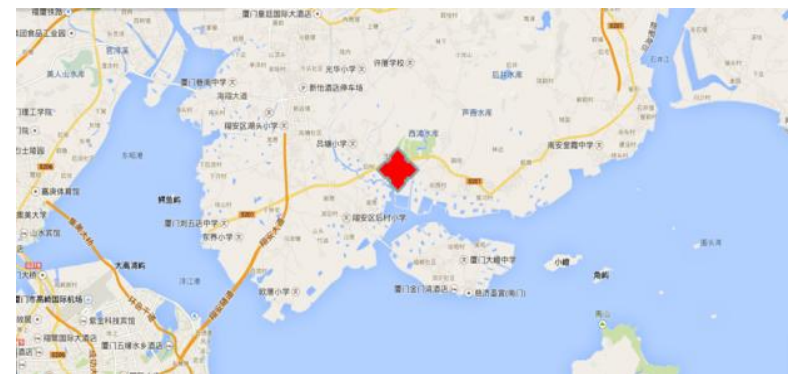

Figure 1. Geographical Location of Tungyuan Village

Xiangan District belongs to subtropical marine monsoon climate with ample sunshine. The summertime is as long as 152 days, while the wintertime is only 29 days. Therefore, a local proverb goes, "There is no intense heat is summer, and there is no cold current in winter." Tungyuan Village used to be a coastal fishing village where villagers make a living by fishing, making solar salt, and raising ducks. The height is declining from the north to the south. Xiangshan is its north border, and the altitude of the peak is 176 meters. Its south is the bay formed between Xiangan District and Dadeng Island. The site of this village is located in the central portion "in front of mountains, in back of sea, and facing sunshine." The terrain is flat with certain slopes. Such a high-quality environment can nourish organisms, as well as satisfy the material conditions of residents living here. This village is the so-called "Treasure land with great Feng Shui." This might be one of the reasons why the new Xiangan Campus of Xiamen University chose this site.

\subsection{Psychological Factor - From Feng Shui to Environment}

The area of the architectural complexes site is approximately 3 $\mathrm{hm}^{2}$ with about 150 residential complexes, including one giant auditorium and one ancestral hall. Most of the complexes were built in 1920s-1980s by the clans of the Changs. The building of Minnan residential complexes attached importance to the details, and Feng Shui masters would be invited to choose the site first. Feng Shui masters would use compass to determine the residential orientation first, which is called "Qiangeng (牵 庚) " There were taboos against directly facing the four orientations (south, north, east, and west), and only residence of nobles and temples could directly face the four orientations. General residential complexes had to deviate by a certain angle, which is called "to be compatible" with orientations (Tsao, Chuang, and $\mathrm{Wu}, 2008$ ). The site selection of ancient residential complexes in Tungyuan Village was no exception. The overall layout faces the south, and the complexes deviate by $5^{\circ}$ in the west or east from the north-south axis (Figure 2).

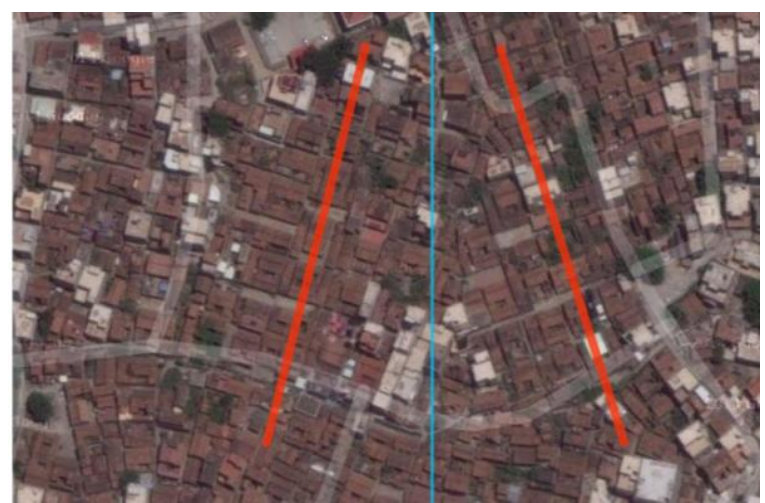

Figure 2. Architectural orientation of residential complexes of the Changs in Tungyuan Village deviates by $5^{\circ}$ in the left and right

Tungyuan Village is a naturally formed village, and thus is called Tungyuan naturally Village. Although it is formed naturally, the overall layout of the entire village seems to follow certain rules. In addition to deviating by $5^{\circ}$ in the west or east, every building in the village is at a horizontal interval of approximately 1 meter. The 1 -meter interval can serve as sidewalk, as well as for fire prevention and drainage. A "Cheng

(坮)" at the width of approximately 6 meters was left in front of most of the buildings. The Cheng of several households connected with one another to form an even larger Cheng. Such "Cheng" enabled every household to have their own independent space, and were also the open public spaces where villagers gathered to chat with one another. Besides, such flat grounds could also be used for solarization (Figure 3). All in all, the village was connected by the lines formed by the road shape at the width of 1 meter. Flat grounds of various scales formed the planar public space. There were also dot-shaped spaces formed by giant auditoriums, and ancestral temple. The entire village was composed of such points, lines, and planes that assumed their own responsibilities to form perfect rhythms.

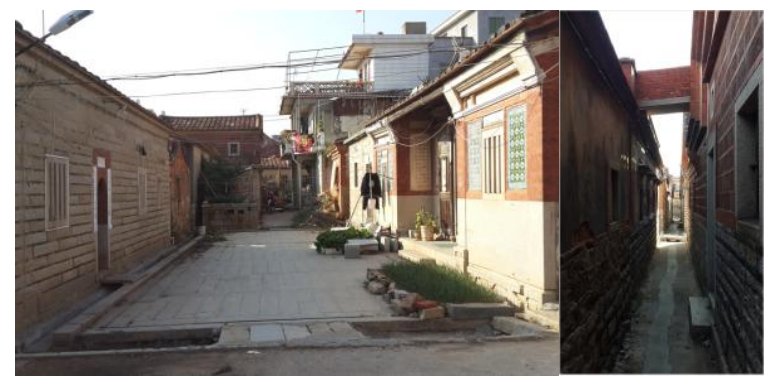

Figure 3. "Cheng" in front of the ancient residence of the Changs and the 1-meter interval

\subsection{Summary}

Since the ancient times, people have been extremely careful about site selection of settlement. The structural layout of the overall settlement of Tungyuan Village reflects that, from the perspective of material basis, this village has superior natural geographical environment; from the perspective of psychological factor, this village was completely built according 
to the pursuit of ideal Chinese Feng Shui (Figure 4). In modern language, such great Feng Shui can be explained as: "The village is in front of mountains and in back of plains where the streams at two sides converge. The village is surrounded by mountains in the left and right where there are tall trees flourishing luxuriantly." The site section of Tungyuan Village almost followed every rule of Fang Shui in the model as follows. Tungyuan Village is exactly located at the area of "dragon's lair.”

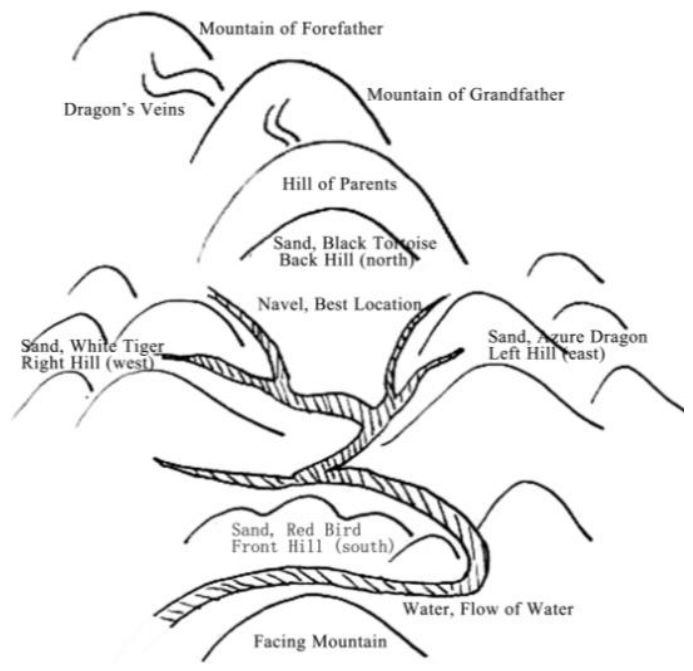

Fig 4. A representation of the ideal Feng-shui composition.

\section{BASIC PATTERN OF SINGLE RESIDENTIAL BUILDINGS - TAKING THE RESIDENCE OF THE CHANGS LAO SAN FOR EXAMPLE}

This survey selected the historic residence of Huan-wen Chang in Tungyuan Village as the object because this huge historic residence exists for a longer period of time, more complete architectural details are preserved, partial decoration is quite abundant, and architectural layout is more typical (Figure 5). This building is called "historic residence of Chang Lao San" in the following sections because the neighbors all call Huan-wen Chang as "Chang Lao San," the third son among siblings. In the survey on ancient architecture, residences are also usually named after names of owners.

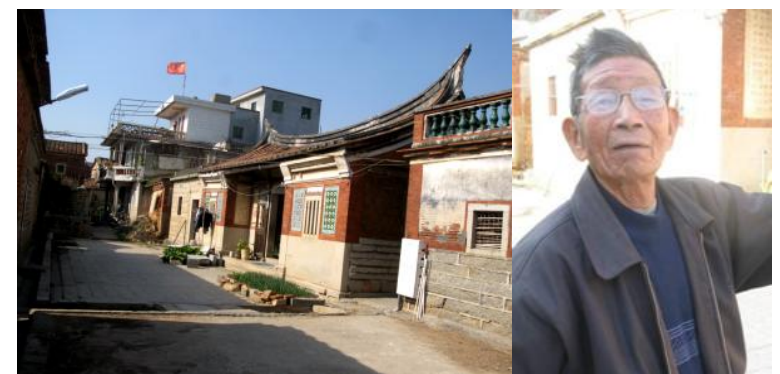

Figure 5. Historic residence and Owner, Chang Lao San

Chang Lao San, a.k.a. Huan-wen Chang, was born in 1931. His race is Han, and is currently 84 years old. According to the introduction of Chang Lao San, this historic residence has existed for more than 8 decades. It was built when he was 4 years old. However, he was too young to can't remember all of the details about the building of his own house. At the time, every residence in the village looked the same. He also heard of the process of residence building of some of other households, as well as many stories about residence building. Therefore, Chang Lao San played a very important role in this survey on historic buildings, and also provided some valuable information. His assistance in this study is hereby highly appreciated.

\subsection{Overall Architectural Layout}

3.1.1 Planar Layout: The ancient name of Fujian is "Min" where Baiyue people lived. Due to the endless wars in central plains in the Qin and Han Dynasties, people in the north constantly moved south. Therefore, the development of aboriginal culture of Baiyue people in Min was terminated, and the highly developed political, economic, and cultural systems of central plains were introduced. As a result, the architectural form of courtyard house in the north is preserved.

The historic residence of Chang Lao San is the typical architectural form in Minnan. its main feature is as follows: Cheng is before the rear is Cuo, Facing south, Three bays with double Hucuo, Red brick and White stone wall, Architectural form of Hard mountain type roof and Double cocked dovetail ridge. "Bright hall and dark rooms" is the layout feature of historic residence in Minnan. The central hall for worshipping ancestors and gods and treating guests is wide and bright. The posterior wall of hall is usually made of foldable wooden door, which is generally closed to separate the hall from the posterior space. The posterior space is the stairwell where miscellaneous articles are placed. The eastern and western rooms at the two sides of the hall are the main bedrooms. There are two layers of living space. The "one bright and two dark" three rooms sections structure is also the most fundamental unit of historic residence in Minnan. Such a historic residence is the courtyard house building composed of several single buildings and external spaces based on the layout of "one bright and two dark."

There are rooms in the east and west of the patio called "east jutou" and "west jutou," which are the east wing room and west wing room of courtyard house, respectively. The patio in the center can function as ventilation, lighting, and rainwater collection in hot and humid summer to form a cool environment. Such a residential spatial form of exterior closure and interior openness reflects strong centrality and security (Wang and Luo, 2003).

3.1.2 Housing Allocation and Separation of Households: The Changs has 3 sons. Besides, Lao San's father also has a younger brother, namely, Lao San's uncle. The whole family lives in this historic residence. With the constant expansion of population in the Changs, reasonable housing allocation is also required. According to the Changs' tradition, there are 3 sons and 1 uncle in the Changs, so the house should be divided into 4 parts. In Chinese traditional custom, the left is for the senior, the right is for the junior, and the hall is the axis. Therefore, the housing allocation is: the large east wing room in the left of posterior hall is for Lao San's parents and the oldest brother; the large west wing room in the right of posterior hall and the west Jutou is the Lao San's uncle; the room in the right of the anterior hall is for Lan San's second oldest brother; the room in the left of the anterior hall is for Lao San; the rest of the east Jutou is used as the whole family's kitchen (Figure 6). Such space allocation enables everyone to have their own private space, and the patio and flat ground are their public space. Therefore, reasonable housing allocation is the foundation of harmony among the family members. 


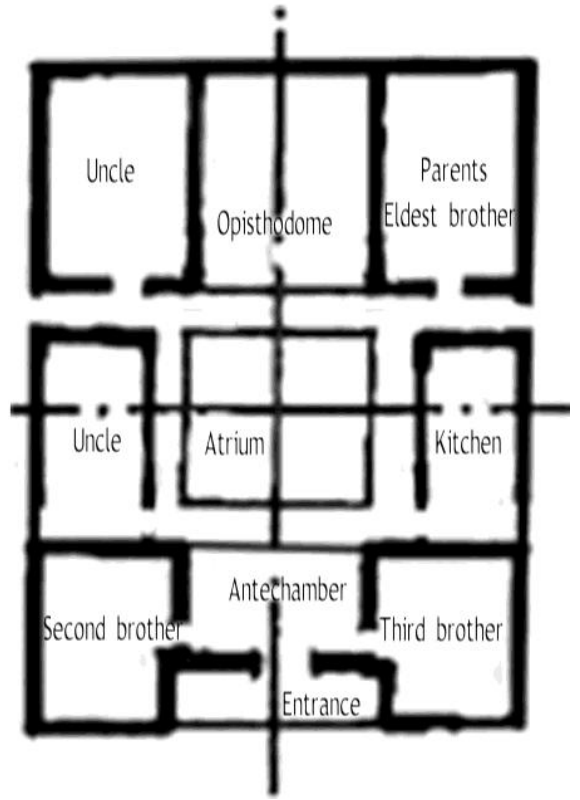

Figure 6. Housing allocation

In Chinese culture, a proverb went, "Trees will divide their branches when growing big, and household of sons should be separated as they grow up." When children all grow up and have their own families, it's the time to start separate the households. Therefore, Lao San's brothers further built three huge residences in the left and right of the ancestral residence and in front of the flat ground. The huge residence of the oldest brother was built first in the right of the ancestral residence. However, it is now a ruin. The residence of the second oldest brother is in the left of the ancestral residence, and is preserved better. However, no one lives in it now, so insects and animals may be attracted to stay in it, which is extremely unfavorable to the preservation of historic residence. Lao San's residence is built in front of his oldest brother's flat ground. However, no one lives in it, either, and the residence is old and shabby (Figure 7). At present, only Lao San lives in the ancestral residence that is preserved well. Therefore, a historic residence cannot be preserved for a long period of time unless there are people living in it. If there are no people living in a historic residence, it will pass away.

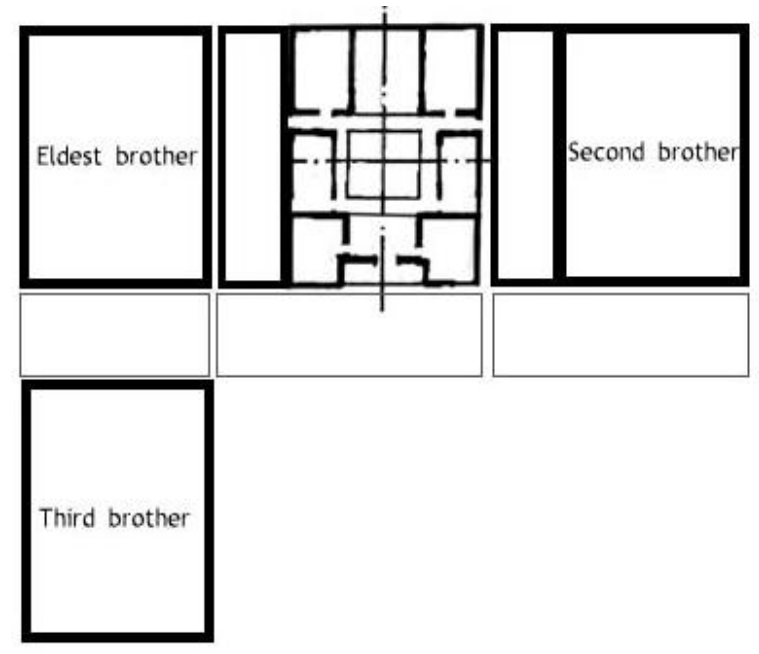

Figure 7. Separation of households
3.1.3 Golden Ratio of Historic Residence: Golden ratio reflects strict proportionality, art, harmony, and abundant aesthetic value. There exists a perfect golden ratio in almost all of the animals and plants in the nature. The golden ratio of length and width is $1: 1.618$. For example, sunflower in plant kingdom has 89 petals, with 55 of them facing one direction and 34 of them facing the other direction. The ratio of these two numbers is the striking ratio of 1:1.618. Taking the well-known beautiful marine organism, nautilus, for example, it has perfect golden spiral ratio. Designers also frequently apply this classical ratio to their own design works. Since there exists the perfect golden ratio in the nature and human beings are one of the animals in the nature, can people create historic residences with golden ratio out of animal instinct under the situation where building materials and architectural conditions are limited in ancient times? This study applied the golden spiral ratio to the floor plan of the changs' historic residence, and discovered that there is a high degree of overlap between them. This fact shows that, although ancient people did not use western rational scientific methods to design houses when building them, they still created the beautiful ratio of historic residences out of their instinct to beauty (Figure 8).

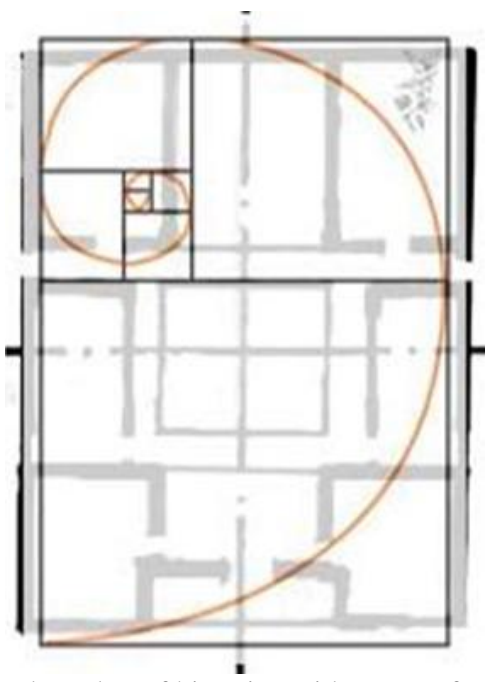

Figure 8. Floorplan of historic residence conforms to the golden ratio

3.1.4 Drainage System: Historic residences in Minnan are called "houses that will never be flooded," and the mystery is their exquisitely designed drainage system. Similar to other historic residences, the drainage outlet of Lao San's residence is also set up at the patio. When a pot of water is poured into the one and only drainage outlet, it will be drained out soon. This small drainage outlet is called "cat hole." There is one "cat alley" (a place where cats play) at the two sides of the house, respectively (Figure 9). Cats and other small animals can pass through cat alley where water can be drained out as well. In rainy days, rainwater passes through "cat hole," and then is drained out from the cat alleys at the two sides of the house to the sewer in the 1-meter interval between residences and eventually drained into river. Therefore, historic residences are seldom flooded. As a matter of fact, the most critical factor is that the Changs' ancient village faces the south and the height is declining from the north to the south. The ancient people followed the scientific rule of "water flows downhill" to design the drainage system. Therefore, historic residences have never been flooded. 


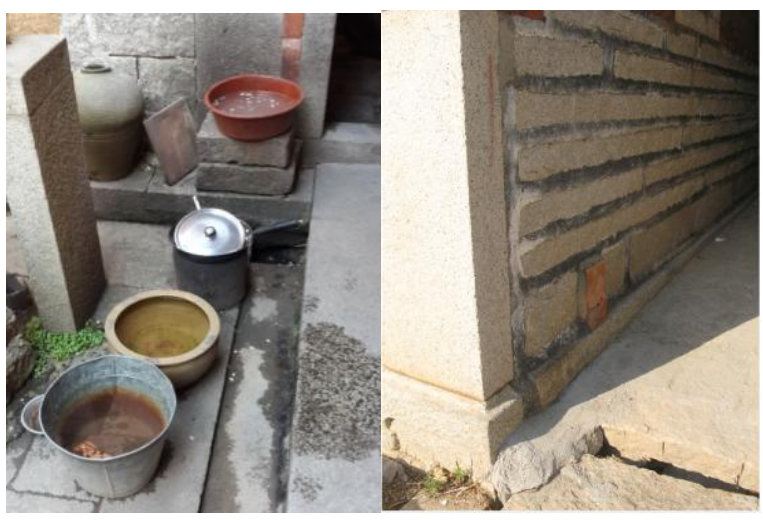

Figure 9. Drainage outlet of patio and cat alley

\subsection{Building Materials}

Minnan areas are surrounded by mountains and sea, and thus are rich in natural resources. The famous building stone materials include "Quanzhou white" in Shipan Nanan, "Fengbai" in Wufeng, Huian, and "Qingdou stone" in Yuchang Lake. Besides, there are also other mineral resources, such as kaolinite and limestone. Under the influence of subtropical marine monsoon climate, the soils in Minnan areas are mainly red soil and clay soil. There are many forests and plantations in Minnan. Timber is produced in mountain areas, and the main building materials include fir, pine, and camphor. The tall and straight fir that can be easily hewed is particularly a great building material (Tsao, Chuang, and $\mathrm{Wu}, 2008$ ).

The fir and red bricks used in Lao San's residence are both from Shima in Zhangzhou. The stone material is the Quanzhou white from Quanzhou, and the tiles are produced locally. It is worth mentioning that the exotic colorful tiles in front of the building can only be seen at Chang Lao San's historic residence in the entire village. Such tiles seem quite eye-catching and beautiful. These exotic tiles are from Philippines, and are also the southeastern culture brought back by the Chang brothers after they returned home from running business abroad (Figure 10). Since the ancient times, Minnan areas have frequently interacted with other countries, and have been strongly affected by marine culture. Moreover, the emigration of overseas Chinese engaging in business in the early days and their return to China also significantly imprinted residents in Minnan with exotic culture.

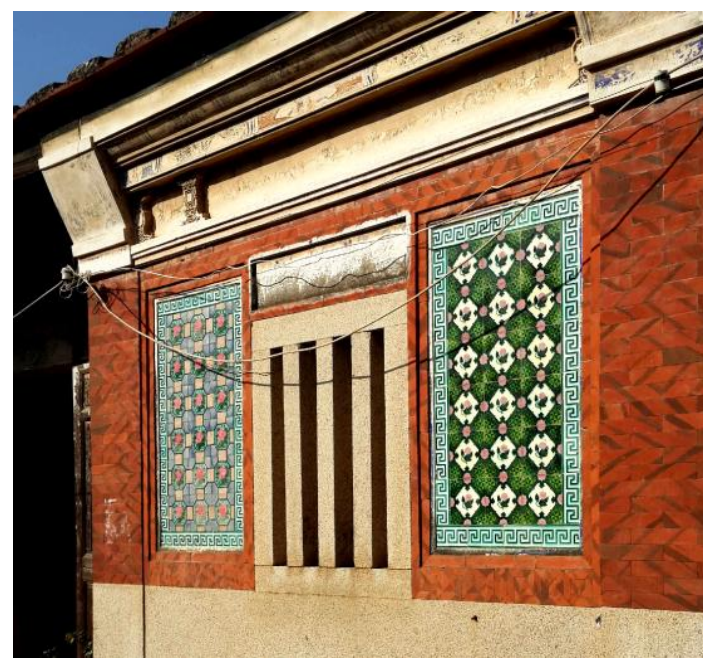

Figure 10. These exotic tiles are from Philippines

\subsection{Architectural Structure}

The typical traditional residential complexes in Minnan are "palace-style" huge residences. The architectural features of such "palace-style" residential complexes are directly associated with courtiers moving south from the central plains in ancient times. The features of architectural layout of "palace-style" huge residences are axial symmetry, multi-layer depth, connection between front and back and left and right, and symmetrical configuration. Such features of architectural layout have been inherited since the Qin Dynasty. "Palace-style" huge residences are generally four-pillar three rooms or six-pillar five rooms. The configuration of various rooms of a huge residence is certainly symmetrical. As a result, the architectural layout where a hall is the axis and patio is the center is formed.

Most of the "palace-style" huge residences are Chuandou-type timber houses. Tenon is used to connect wooden components, such as pillar, beam, square cylindrical timber, sandalwood, and rafter, to bear the weight of roof. On the other hand, walls are not weight bearing and can only function as separators. For example, some of the walls separating the hall from huge room are made of weaved reeds or bamboos, with plaster pasted outside. Some of the walls of hall and rooms are purely made of wood, and such walls are shockproof due to light weight. Because of the Great Clearance of Minnan areas in the late Ming and early Qing Dynasties, residential complexes were turned into ruins. Therefore, many walls of ancient residential complexes in the Qing Dynasty are made of "the mixture of old tiles, stones, and bricks," which becomes an architectural feature with historical and cultural insight.

3.3.1 Beams and Lamp Beams: Installation of central beam is an important procedure during house building. The beam herein refers to "central beam," namely, "Jiliang" and "Jiyuan." It is necessary to choose an auspicious date to install the central beam. The central beam should be installed by chief carpenter, which is called "initiation of beam installation (开斧做梁).” During the initiation of beam installation, carpenters also have to say auspicious words. For example, the carpenters in Quanzhou read auspicious words when hewing beams: A green dragon rests in a mountain. Lu Ban uses it in the world. To initiate beam installation on an auspicious date, an everlasting house can be built. Let's become rich ... (一条青龙在高山, 鲁 班取来在阳间, 良辰吉日开金斧, 民丁盖起万年祖。发 啊... ) (Tsao, Chuang, and Wu, 2008). Chang Lao San's anterior hall has a total of 7 beams, while the posterior hall has a total of 9 beams. 7 and 9 are both odd numbers. In Feng Shui, odd numbers are called Yang numbers, as well as auspicious numbers. The layout of anterior hall and posterior hall is also the architectural layout of low front and high back. Such an architectural layout meets the needs of visual angles, as well as psychologically attaches importance to the main position of hall.

Lamp beam is also called lamp pole. In general, lamp beam is installed on the connection beam between Jiyuan and Xiafuyuan in the bright anterior hall. There may be carved "lamp holders" at the two ends, with lamp holders embedded on the wall. Lamp beam is not structurally functional, and is only used to hang lanterns in huge residence, ancestral temple, and temple. In Minnan language, the pronunciation of "lamp" is the same as that of "Ding." According to Xiamen Customs in <Xiamen Gaxeteer> published during the reign of emperor Daoguan: "On lantern festival, ... women wear colorful clothes to offer lotus lamps, red oranges, candles or money to temples (in Minnan 
language, lamp means to pray for good luck on having offspring)." Therefore, hanging a lantern on lamp beam means to pray for good luck of having offspring. Lamp beam is installed upon completion of house building. During the installation of lamp beam, it is necessary to hold a ceremony (Tsao, Chuang, and Wu, 2008). The lamp beam should mainly be painted in red, and should be the most gorgeous component of house framework. Even though the house is not painted in colors, a lamp beam has to be painted in colors. In Chang Lao San's residence, only lamp beam and central beam are painted in red and other colors, while other beams are not painted (in wood color), suggesting that the owner attaches importance to lamp beam and central beam. The eight trigrams diagram is painted under some of the central beam or lamp beam to protect the house and ward off evils (Figure 11). In addition, lamp beam also functions for spatial division. It is the spatial division between gods and human beings, that between the saint and the common people, and that between interior and exterior. Lamp beam is also the symbol of folk culture.

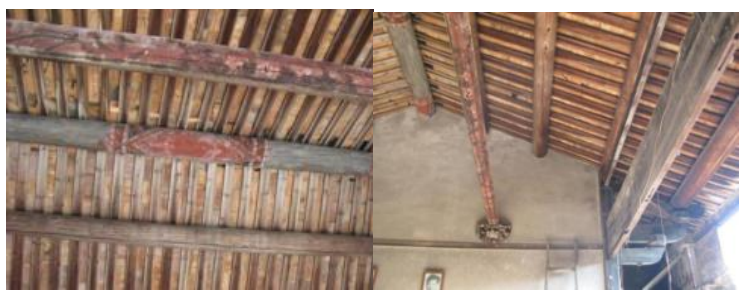

Figure 11. Central Beams and Lamp Beams

3.3.2 Dougong: Dougong is the classic masterpiece in Chinese architectural structures. In mechanics, Dougong not only can disperse power, but also is shockproof. Dougong is usually used by rich families to show off their money, as well as an important decoration object. It will be exquisitely crafted, painted, and gilded, and is rich in artistic value. Common people will not ignore the decoration of Dougong, either, and tend to carve it with simple decoration patterns to express how they value it. In Chang Lao San before and after the architectural of the wood of hall Dougong do the simple decorative sculpture, But it is very interesting, the East and West Jutou did not do Dougong, but with a simple stone similar to the cantilever beam. It is well known that in the mechanics of stone material is not suitable to do the diagonal brace, the stone material is pressure resistance and no toughness, made of cantilever beam tends to have a considerable shear force caused damage. But in Minnan this practice is very common, in the experience of the craftsmen, the stone can also be used very appropriate (Figure 12).

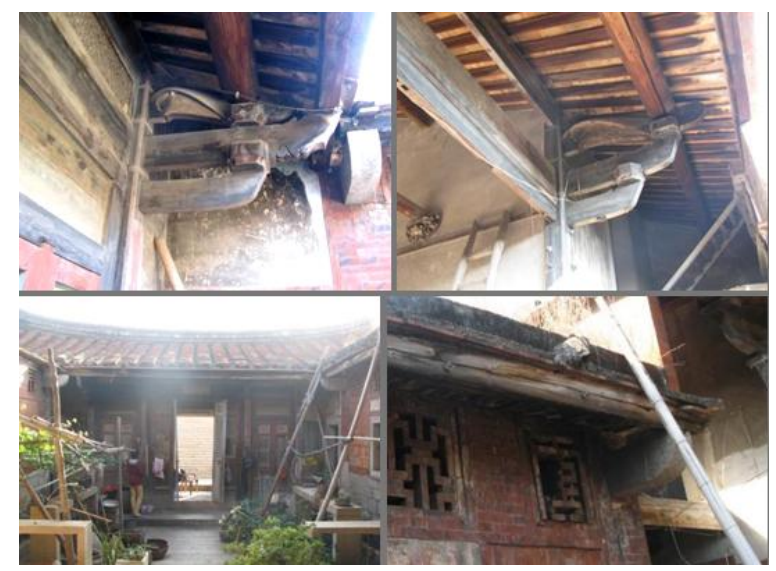

Figure 12. wood Dougong and a simple stone similar to the cantilever beam.

\subsection{Architectural Decoration}

The decoration of historic residential complexes in Minnan is also quite abundant and colorful. Red bricks or tiles are used to build the front walls or main walls of historic residential complexes in Minnan. Lime is used to fill the gap with auspicious letters, such as "fortune," prosperity," and "longevity," as well as patterns, such as swastika, eight trigrams, turtle shell, and blossom. In addition, specific red bricks carved with flower patterns are used to decorate front door and hallway. Such carving tends to be applied to two sides of front door, drainage system, veranda, and the surroundings of patio. The carving is mainly the portrayal of everyday life of "fishery, forestry, farming, academia, government service, agriculture, industry and commerce." Patterns, such as pot, bottle, bell, vessel, flower, bird, fish, and insect, as well as widely spread classical literature materials and historical stories, such as "The Twenty-four Filial Exemplars" and "Fengshen Yanyi," that symbolize fortune are also used in carving. The refined stone carving is reflected in various carved pillars and beams, stone pillows, and carved windows. In general, the patterns, trims, and hallway painted using lime under eaves of historic residence and the ink wash painting or colorful painting on the lime wall nearby the corridor also reflect elegant and exquisite works (Yan, 2010). Such decoration is also reflected in Chang Lao San's residence. For example, there is wood carving of "plum, orchid, bamboo, and chrysanthemum" on the windows, and there are also exquisite bat pattern and vessel pattern symbolizing peace and safety carved on the altar in the hall. The colorful painting and carving of residential complexes focus on the front side of building, and there is special decoration under eaves because the front side of building represents the style of owner. There are many exquisite colorful paintings and carving on the front side of the building. The themes are associated with longevity, such as "pine and crane that symbolize longevity" and "fortune, prosperity, and longevity," and there are also many children-related themes to reflect the owner's expectation towards offspring, as well as scholar sentiment.

\subsection{Reflection of Architectural Self-defense}

The reflection of architectural self-preservation is particularly significant in residential complexes. For example, buildings, such as tulou, hill fort, and Hakka walled village in Fujian all function as self-defense. In the past where there were wars, riots, and incomplete legal system, everyone had to engage in selfdefense to live safely. Lao San's historic residence reflected both psychological self-defense - Feng Shui, and material selfdefense - "security doors and windows," which both reflect the unique architectural cultural meaning of residential complexes in Minnan.

Although the round doorknob made of brass on the front door of Chang Lao San's residence is shabby now, it reflects the beauty of ages. The careful observation shows that, there is an eight trigram carved around the round shape. In general, in Feng Shui, the eight trigram diagram can ward off evils, and is used to defend residents from external filth. A "security door" is installed inside the front door of the building. There are 3 poles at a diameter of $15 \mathrm{~cm}$ placed beside the 3 notches around the interior side of the front door. The 3 poles can be firmly inserted behind the front door, if necessary. There are also solid wood bolts installed inside the side doors and windows, so it is very difficult for thieves to break in (Figure 13). Such a traditional architectural feature of residential complexes in 
Fujian reflects the defensive feature of Chang Lao San's residence, as well as owner's self-defense.

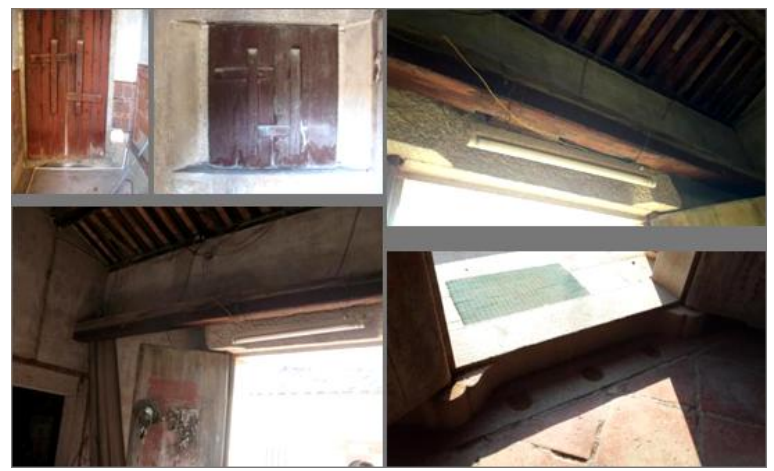

Figure 13. Historic residence's security doors and windows

\section{SUGGESTIONS ON PRESERVATION AND MAINTENANCE OF THE CHANGS' ANCIENT RESIDENTIAL COMPLEXES}

\subsection{Current Status of Historic Residence}

The essences of traditional residential complexes in Minnan truly exist among the people. Numerous existing ancient residential complexes in Xiangan since the Ming and Qing Dynasties are one of the most typical ancient residential complexes in Xiamen and Fujian. Jian-nan Ting, committee member of Xiamen City Siming District Committee, claimed that, owners of ancient residential complexes do not value the protection of historic residences, especially when the current compensation for demolition is high due to real estate fever. To obtain more compensation for demolition, many owners of ancient residential complexes in the suburbs have demolished the one-storied ancient building to build multi-storied modern building one by one, which is one of the reasons many ancient buildings have been thoroughly demolished. In addition, some of the owners of ancient buildings are unable to maintain them. In Xiamen, there are only a very few ancient buildings with cross-strait culture that are completely preserved. However, many historic residences have not been classified by cultural preservation authority as protected objects or corresponding measures have not been taken. At present, only the ancient buildings that have been classified by cultural preservation authorities at all levels are effectively protected. Most of the ancient residential complexes and settlement of ancient buildings owned privately are facing the risk of disappearance due to the lack of protection and maintenance. The current status of historic residence is not optimistic. Although various local governments have proposed some relevant policies to protect historic residence, the effect is significantly limited.

\subsection{Suggestions on Preservation and Maintenance}

The historic residences in Tungyuan Village possess superior geographical location, climate, and environment. They are in front of Xiangshan, and face the sea. Tungyuan Village is a rare place with great Feng Shui. In addition to the superior natural environment, it also has abundant cultural and historical background. After the new campus of Xiamen University settled down in October 2012, the population suddenly increased, which also enabled the Changs' historic residence in Tungyuan Village to gradually attract the attention from people. Due to the lack of appropriate propaganda policies and protective measures, it is very difficult for historic residences in Tungyuan to reflect their charm in a short period of time. Therefore, this study intends to take the opportunity to aggressively advocate and promote the "red brick culture" in this place, as well as the traditional folk culture in Minnan. It is hoped that the owners of historic residences, high school teachers, students, and young entrepreneurs can aggressively participate in the protection and development of historic residences and endeavor to reflect their charm to attract more people's attention. During the development, the industries, such as historic residence B\&B, local cuisines, and cultural creativity, can be developed. In addition, university students can also take the opportunity to train themselves. In the end, it is also hoped that the government can encourage young entrepreneurs to aggressively participate in the protection of historic residences to enable the ancient residential complexes in China to be passed on generation by generation.

\subsection{Suggestions on Protection of Historic Residences in Minnan}

Individuals, government, and the entire society all should make efforts in protection. Suggestions on protection of historic residences in Minnan:

1. The offspring of historic residences should aggressively protect and repair them.

2. Relevant government authorities should conduct a general survey on historic residences in various townships and register them one by one to archive them for reference.

3. It is necessary to establish an expert appraisal team to appraise the registered historic residences and classify historic residences with protection value into protected objects. In addition, the government should provide financial support and organize personnel to engage in repairs.

4. Education and propaganda departments should aggressively advocate the importance of protection of historic residences to enable more people to participate in the protection of historic residences.

5. It is necessary to discover the important value of historic residences in Minnan, develop historic residence tourism, and increase the influence of historic residences to protect historic residences through development.

6. Relevant departments should strictly punish those who steal and illegally sell furniture, wood carving, and stone carving of historic residences.

7. It is necessary to apply for registration in "China World Heritage Tentative List" and "World Heritage Catalogue" of cultural assets with great impact in Minnan and historic residences in Minnan with cultural preservation value.

\section{CONCLUSION}

In Minnan dialect, "Qi Cuo" is house building, which is a very important thing to people in Minnan, as well as the most representative traditional culture in Minnan. House building reflects the wish for beautiful life of people in Minnan, and forms unique cultural meanings. In typical rural life of Chinese traditional society, three major elements - housing, education, and worshipping are certainly included. These three major elements all are reflected in the residential complexes in Minnan. Strict and exquisite layout conception reflects on how to sustain family with profound intelligence. In addition, it is hoped that more people can pay attention to historic residences, protect them, and develop the preservation of them. The profound cultural meanings in historic residential complexes in Minnan are worthy of exploration. 


\section{REFERENCES}

Tsao, C.P., Chuang, J.H., and Wu, Y.D., 2008. Minnan Architecture. Fujian People's Publishing, pp. 132-136.

Wang, L. and Luo, C., 2003. The Tsais' Ancient Residential Complexes. Journal of Northern Jiaotong University, 27 (1), pp.87-93.

Meng, S.H., 2014. Jian-nan Ting, Chairman of Fujian Province Collector Association Appeals for Attracting Famous Cultural Experts to Live in Historic Residences in Minnan to Protect Them. Fujian Daily, 16.

Lu, H.W., 2012. There are Historic Residences that "Will Never be Flooded" in Xiamen - Liantang Villa and the Lees' Ancestral Temple in Jimei. Strait Herald, 11.

Yan, C.C. Architectural Artistic Styles and Decoration of Ancient Residential Complexes in Minnan: http://wenku.baidu.com/view/237132d476eeaeaad1f33091.html

Golden Ratio - Design Tool of Designers: http://wenku.baidu.com/view/1837f2691eb91a37f1115c7e.html

Chuang, Y.F. Unique Ancient Residential Complexes in China Historic Residences in Minnan: http://wenku.baidu.com/view/c7ae100303d8ce2f0066232d.html

Baidu Baike-Minnanancient residential complexes: http://baike.baidu.com/view/15042290.htm

Blog of Historic Residences in Lanqin, Xiamen - Prospects and Suggestions on Protection of Historic Residences in Minnan: http://blog.sina.com.cn/s/blog_4082d8a10100wmep.html 